\title{
A Defined Medium for Mycoplasma Strain Y
}

\author{
By A. W. RODWELL \\ Division of Animal Health, Animal Health Research Laboratory, C.S.I.R.O., \\ Parkville, Victoria 3052, Australia \\ (Accepted for publication I3 May 1969) \\ SUMMARY
}

\begin{abstract}
In a defined medium for Mycoplasma strain $Y$, a mixture of the diacetoxysuccinoyl esters of monoolein and monopalmitin replaced unesterified fatty acids and serum protein fractions, enabling the minimal growth requirements to be determined. Other Mycoplasma strains did not grow in media in which these esters replaced fatty acids and protein fractions.
\end{abstract}

\section{INTRODUCTION}

Good growth of Mycoplasma strain $\mathrm{Y}$ was obtained in a medium containing defatted bovine serum albumin to bind fatty acids and a heat-stable serum protein fraction to disperse cholesterol (medium $\mathrm{C}_{2}$, Rodwell, I969). The amino acid, peptide and growth factor requirements of strain $\mathrm{Y}$ were determined in a protein free medium (medium $\mathrm{D}$, Rodwell, 1967) in which fatty acids were added in growth limiting concentrations. Growth in medium D was poor and might have been limited by nutrients other than fatty acids, while the protein supplements might have contributed unrecognised nutrients in medium $\mathrm{C}_{2}$. A completely defined medium giving good growth of strain $Y$ is described in this paper. Some observations on the nutrition of other strains are also reported.

\section{METHODS}

Organisms. Strain Y, isolated from a goat (Laws, 1956), resembles Mycoplasma mycoides in its nutrition and metabolism (Rodwell, I960, 1967), but differs in that its growth is not improved by aeration. The following strains were also used: v5, GLADYSDALE and $\mathrm{KH}_{3} \mathrm{~J}$ of $M$. mycoides; the CHU strain of $M$. mycoides var. capri; strains $\mathrm{N}_{29}$ and L 29I7, isolated from bovine arthritis, and s6 (M. gallisepticum).

Growth assays. These were performed as described previously (Rodwell, 1969). Cultures of strain $\mathrm{Y}$ were incubated vertically without agitation at $37^{\circ}$; cultures of the other strains were incubated in the same way and also in an inclined rack which was rotated at $10 \mathrm{rev} . / \mathrm{min}$. (rotated tube cultures).

Growth was measured by turbidity at $660 \mathrm{~m} \mu$; by the incorporation of ${ }^{3} \mathrm{H}$ thymidine (Rodwell, 1969), or by protein determination, by the method of Lowry, Rosebrough, Farr \& Randall (195I) with crystalline bovine serum albumin dried to constant weight as standard, in cells washed in $0.25 \mathrm{M}$-sodium chloride $+0.02 \mathrm{M}$-sodium phosphate $\left(\mathrm{pH}_{7} \cdot 4\right)+0 \cdot 0 \mathrm{I}$ M-magnesium sulphate.

In some cases, an accumulation of pyruvate during growth suggested a defect in the pyruvate oxidase system, and cells were then examined manometrically for pyru- 
vate oxidase activity. The preparation of cell suspensions, and amino acid supplement for manometric experiments, were described previously (Rodwell, I967).

Media. Media C, C I and C2 were as described (Rodwell, 1967, 1969). Medium C 3 had the same composition as medium $\mathrm{C}$ except that the concentrations of glycerol and of 'fatty acid poor' BSA were increased to $0.02 \mathrm{M}$ and $2.7 \mathrm{~g}$. $/ 1$. respectively, that of sodium phosphate was decreased to $0 . \mathrm{I} \mathrm{I} \mathrm{M}$ and sodium DL-lactate $(0.03 \mathrm{M})$ and fraction $\mathrm{C}(0.8 \mathrm{~g} . / 1$.$) were added.$

Alanyl peptides were obtained from Yeda Research and Development Co., Rehovoth, Israel. TEM-4T was a product of Hachmeister Co., Pittsburg, Pennsylvania. It had a fatty acid composition of 28 mole palmitic acid, I9 mole stearic acid, 42 mole oleic acid and smaller amounts of palmitoleic and linoleic acids per 100 mole fatty acid. Other medium components were as described previously (Rodwell, 1969).

Synthesis of diacetoxysuccinoyl esters of monoglycerides. Monopalmitin was synthesized by reaction of DL-isopropylidene glycerol with palmitoyl chloride (Baer \& Fischer, 1945). The product (m.p. $76-76 \cdot 5^{\circ}$ ) was chromatographically pure by thin layer chromatography (t.l.c.). Monoolein was synthesized by direct esterification of glycerol (Hartman, 1957). The product (m.p. 33.5-34.5 ) contained no diglyceride or other impurities detectable by t.l.c.

Reaction of diacetyl D-tartaric acid anhydride (m.p. $1334^{\circ}$ ) with equimolar amounts of the monoglycerides at $110^{\circ}$ in the absence of a cosolvent gave a complex mixture of products. Reaction in boiling chloroform gave a less complex mixture, while in the presence of pyridine it proceeded rapidly and gave only two major products. A solution of monoolein ( $2 \mathrm{mmoles}$ ) in Io $\mathrm{ml}$. dry chloroform was concentrated by distillation to $5 \mathrm{ml}$. Diacetyl tartaric acid anhydride (2.I mmoles) and dry pyridine ( $4 \mathrm{mmoles})$ were then added. After $30 \mathrm{~min}$. at $65^{\circ}$, a thin layer chromatogram-solvent chloroform + methanol + acetic acid + water $(84+15+5+2$ by vol.) - of the reaction mixture showed, in decreasing order of mobility, a small amount of unreacted monoglyceride, traces of unknown products, a very heavy spot (fraction OT/I) and a smaller amount of another product (fraction OT/2). Fractions OT/I and OT/2 were purified by chromatography on a column of silicic acid. The column ( $40 \mathrm{~g}$. silicic acid) was prepared and washed in chloroform + methanol $(100+2 \mathrm{v} / \mathrm{v})$, and the sample (I g. reaction products) applied in the same solvent. The components were eluted with $600 \mathrm{ml}$. chloroform + methanol $(100+2)$ which eluted unreacted monoolein, traces of unknown products and fraction $\mathrm{OT} / \mathrm{I}$; and $300 \mathrm{ml}$. chloroform + methanol $(\mathrm{I} 00+5)$ which eluted fraction $\mathrm{OT} / 2$. Fractions $(25 \mathrm{ml}$.) were collected and examined by t.1.c., and those containing the pure components OT/I and OT/ 2 were combined. The residues after evaporation of solvents were dissolved in methanol, and pyridine was removed by stirring with an excess of Dowex $50\left(\mathrm{H}^{+}\right)$ion exchange resin washed and suspended in methanol. The yields of fractions OT/I and OT/2 were about 50 and $25 \%$ respectively of the starting materials. The corresponding monopalmitin derivatives, which migrated like OT/I and $\mathrm{OT} / 2$ on t.l.c. plates, were prepared in the same way (fractions PT/I and PT/2). The m.p. of fractions OT/I $\left(-8^{\circ}\right.$ to $\left.-6^{\circ}\right)$ and PT/I $\left(34^{\circ}\right.$ to $\left.36^{\circ}\right)$ were similar to published values for $\mathrm{I}-O-\left(2^{\prime}(\mathrm{R}), 3^{\prime}(\mathrm{R})\right.$-diacetoxysuccinoyl)-3-O-oleoylglycerol (IIA), and the palmitoyl homologue (IB) respectively (Birnbaum, I955). It was suspected that fractions OT/2 and PT/2 might be I, 2-di- $O$-(2'(R), 3'(R)-diacetoxysuccinoyl)-3- $O$-oleoylglycerol(II A), as and the palmitoyl homologue (IIB). I A and IB would have one titratable carboxyl group and would consume five equivalents of alkali on saponification, while II A and 
IIB would have two titratable carboxyl groups, and consume nine equivalents of alkali on saponification (Fig. I).

Neutralization equivalents were determined by potentiometric titration of solutions in $50 \%(\mathrm{v} / \mathrm{v})$ aqueous ethanol with aqueous sodium hydroxide, and saponification equivalents after saponification in aqueous ethanolic sodium hydroxide at $80^{\circ}$ for $\mathrm{I} \mathrm{hr}$. The values found (Table I) agree closely with those calculated for IA and IB, and II A and II B.

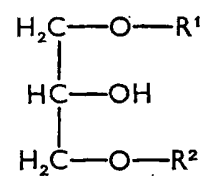

$\mid A R^{1}=$ oleoyl

$\mid B R^{1}=$ palmitoyl<smiles>[R]OCC(CO[R])O[R]</smiles>

IIA R $\mathrm{R}^{1}=$ oleoyl

IIB $R^{1}=$ palmitoyl<smiles></smiles>

Fig. I. Structures of diacetoxysuccinoyl esters of monoglycerides.

Table I. Neutralization and saponification equivalents of diacetoxysuccinoyl esters of monoolein and monopalmitin

\begin{tabular}{|c|c|c|c|c|c|}
\hline \multirow[b]{2}{*}{ Fraction } & \multirow[b]{2}{*}{ Compound } & \multicolumn{2}{|c|}{ Neutn. equiv. } & \multicolumn{2}{|c|}{ Sapon. equiv. } \\
\hline & & Calc. & Found & Calc. & Found \\
\hline $\mathrm{OT} / \mathrm{I}$ & I-O-(2'(R),3'(R)-diacetoxysuccinoyl)-3-O-oleoylglycerol & 573 & 567 & I I 4 & I 14.5 \\
\hline $\mathrm{OT} / 2$ & $\begin{array}{l}\text { 1,2-di- } O-\left(2^{\prime}(\mathrm{R}), 3^{\prime}(\mathrm{R}) \text {-diacetoxysuccinoyl)-3-O- }\right. \\
\text { oleoylglycerol }\end{array}$ & 395 & 400 & $87 \cdot 7$ & $88 \cdot 7$ \\
\hline $\mathrm{PT} / \mathrm{I}$ & $\begin{array}{l}\text { I-O-(2'(R),3'(R)-diacetoxysuccinoyl)-3-O-palmitoyl- } \\
\text { glycerol }\end{array}$ & 547 & 552 & 109 & I I 1 \\
\hline $\mathrm{PT} / 2$ & $\begin{array}{l}\text { 1,2-di- } O-\left(2^{\prime}(\mathrm{R}), 3^{\prime}(\mathrm{R}) \text {-diacetoxysuccinoyl }\right)-3-O- \\
\text { palmitoylglycerol }\end{array}$ & $38 \mathrm{I}$ & 375 & $84 \cdot 8$ & $86 \cdot 0$ \\
\hline
\end{tabular}

\section{RESULTS}

Replacement of proteins and fatty acids by diacetoxysuccinoyl esters of monoglycerides

BSA and unesterified fatty acids were replaced for growth of strain $\mathrm{Y}$ in medium $C_{\text {I }}$ by TEM-4T, a complex mixture of diacetoxysuccinoyl esters of mono- and diglycerides (Fig. 2). The minimum concentration of TEM-4 T required for maximum growth was about $50 \mathrm{mg}$./1. This amount would provide, after complete hydrolysis, a total of $85 \mu$ moles fatty acids. With this concentration of TEM-4T the concentration of cholesterol had to be increased before any growth occurred. The medium was 
then slightly turbid, and some highly refractile microcrystals formed during subsequent incubation.

TEM-4 T was replaced (Fig. 2) by an equimolar mixture of IA and IB and also by a mixture of IIA and IIB. The concentrations of the mixtures, and the proportions of these to cholesterol, were varied: the results shown in Fig. 2 are for the optimum concentrations. Growth with the synthetic homologues was not quite as good as with TEM-4T. They appeared to be more toxic in that the growth-inhibitory concentration of the mixtures was a little lower than with TEM-4T, but the growth was almost as good as with TEM-4 T, and the results obtained by turbidity measurement were confirmed by thymidine incorporation. The yields of cell protein at maximum turbidity were $0.20,0.18$ and $0.16 \mathrm{mg} . / \mathrm{ml}$. culture for media containing TEM-4T, IA + IB, and II A + IIB respectively.

Growth of strain $\mathrm{Y}$ was obtained also when aqueous dispersions of monoolein and monopalmitin were substituted for TEM-4T. Media with these were very turbid and growth had to be measured by thymidine incorporation. Growth was slower and the amount of thymidine incorporated was about $60 \%$ of that in a parallel culture in TEM-4 T medium.

\section{Nutritional requirements of strain $Y$}

Since it is unlikely that TEM-4T would be contaminated with amino acids and water soluble growth factors, requirements for these were in most cases determined in a medium $E$ in which it replaced fatty acids and protein fractions.

Vitamins and coenzymes. Requirements for thiamine, riboflavin and nicotinamide (or nicotinic acid) in a partially defined medium were described previously. Coenzyme A was essential in the TEM-4T medium and could not be replaced by pantothenate, pantethine or pantetheine. Pyruvate accumulated during growth in a partially defined medium (medium B2, Rodwell, I963). This medium probably contained growthlimiting amounts of coenzyme A or other utilizable precursor contaminating one or other of the undefined components. Mycoplasmas grown in it lacked pyruvate oxidase activity, but oxidised pyruvate normally in the presence of coenzyme A (Fig. 3). The abrupt increase in the rate of oxygen uptake with pyruvate as substrate (Fig. 3) did not indicate a change in the rate of pyruvate oxidation, but was due to the accumulation, and subsequent oxidation, of lactate (Rodwell, 1967). With growth-limiting amounts of coenzyme A, growth was accompanied by cellular lysis, presumably because of a failure to incorporate fatty acids.

Growth stimulation by $\alpha$-lipoic acid in a partially defined medium was found previously (Rodwell, I960). The effect of $\alpha$-lipoic acid on growth in medium $\mathrm{C}_{2}$ is shown in Fig. 4. While it stimulated growth in primary culture, it had little or no effect on growth in subculture in the same medium. The pyruvate oxidase activity of mycoplasmas harvested after $20 \mathrm{hr}$ incubation from replicate subcultures in media with and without $\alpha$-lipoic acid was examined (Fig. 5). Mycoplasmas from the deficient culture had no pyruvate oxidase activity, but oxidized it normally in the presence of $\alpha$-lipoic acid. There was no growth response to $\alpha$-lipoic acid in medium $\mathrm{E}$ either in primary culture, or in subculture. Thus it appears that the functioning of the pyruvate oxidase system was not essential for growth of this strain-at least in non-aerated cultures.

Pyridoxin or other vitamin B6 derivatives were not required in the TEM-4T medium 
in which alanine was provided by L-alanyl-L-alanyl-L-alanine (L-ala $)_{3}$. Strain Y grew slowly without alanine or alanyl peptides (see below) and, under conditions where growth was made dependent on alanine synthesis, i.e. in the absence of alanine or of alanyl peptides, growth was stimulated by pyridoxamine (Fig. 6). Growth under these conditions was no better when other derivatives of pyridoxin, including pyridoxal phosphate, were substituted for pyridoxamine. Requirements for biotin, folinic acid or vitamin $\mathrm{B}_{12}$ were not found in any medium.

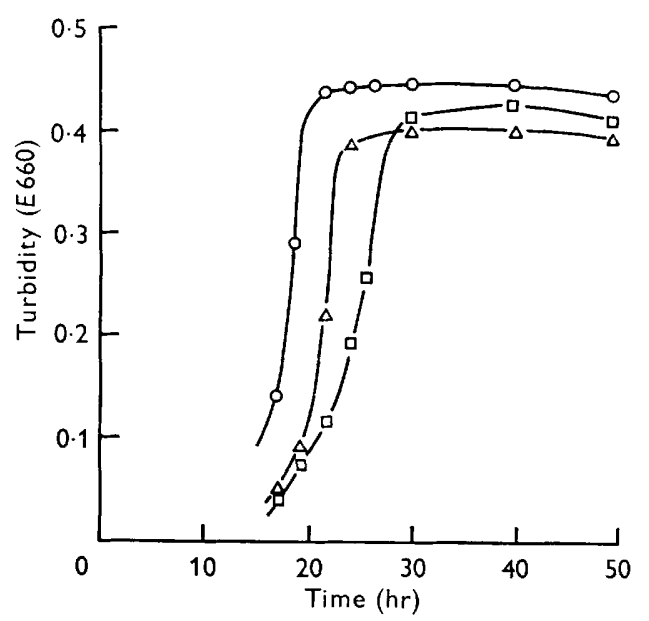

Fig. 2

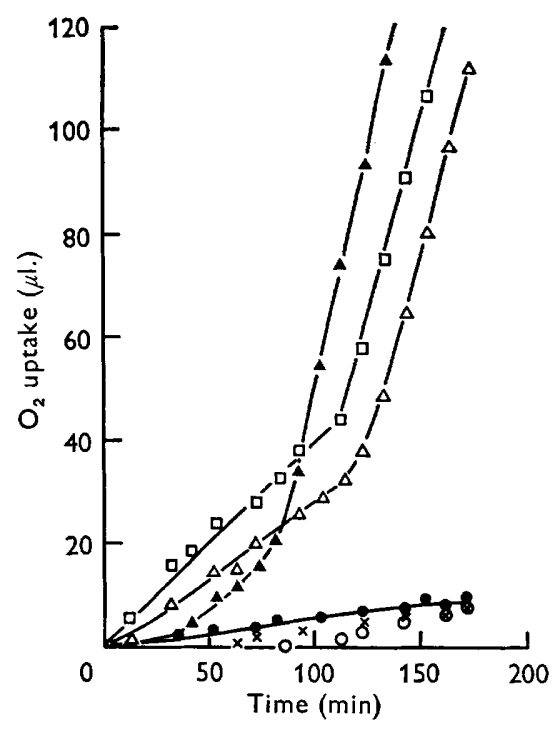

Fig. 3

Fig. 2. Replacement of BSA, fraction $C$ and unesterified fatty acids by TEM-4T or synthetic homologues for growth of Mycoplasma strain $\mathrm{Y}$. The concentration of cholesterol in medium C2 was increased to $200 \mu \mathrm{M}$. BSA, pronase digest of fraction C (PC) and unesterified fatty acids were replaced by: $O$, TEM-4T, $50 \mathrm{mg} . / \mathrm{I}$; $\square$, I A and IB, $40 \mu \mathrm{M}$ each; $\triangle$, II A and II B, $30 \mu_{\mathrm{M}}$ each.

Fig. 3. Effect of coenzyme A deficiency on the pyruvate oxidase activity of Mycoplasma strain Y. Mycoplasmas were grown in medium B2 (Rodwell, 1963) with coenzyme A (coA cells) and without coenzyme A (coA-deficient cells). Manometer flasks contained: $\mathrm{Na}_{2} \mathrm{HPO}$ $+\mathrm{KH}_{2} \mathrm{PO}_{4}, \mathrm{pH} 7.4,200 \mu$ moles; sodium pyruvate, $20 \mu$ moles; coenzyme A (coA), $20 \mu \mathrm{g}$; amino acids, $3.5 \mathrm{mg}$.; coA cells, I.4 mg.; coA deficient cells, $\mathrm{I} \cdot 25 \mathrm{mg}$.; $\mathrm{KOH}$ in centre well. Fluid volume $2.5 \mathrm{ml}$. $\Delta$, coA-deficient cells with $\operatorname{coA} ; \mathrm{O}$, coA-deficient cells without coA; $\square$, coA cells with $\operatorname{coA} ; \triangle, \operatorname{coA}$ cells without $\operatorname{coA} ; 0$, coA-deficient cells with coA, but no pyruvate; $\times$, coA cells with coA, but no pyruvate.

Amino acid requirements. Absolute requirements for all amino acids except glutamic acid, aspartic acid and cystine were reported previously in medium D (Rodwell, 1967). This was confirmed in the TEM-4T medium in which alanine was provided by the tripeptide $\left(\mathrm{L}-\mathrm{ala}_{3}\right)$. In contrast to the results obtained earlier, there was good growth when L-alanine at a concentration of I mM was substituted for alanyl peptides, and slow growth in the absence of alanine or alanyl peptides (Fig. 6). Higher concentrations of L-alanine ( $8 \mathrm{~mm}$ ) inhibited growth, and this inhibition was partly reversed by increasing the glycine concentration. Growth with the tripeptide $\left(\mathrm{L}-\mathrm{ala}_{3}\right)$ and tetrapeptide $\left(\mathrm{L}-\mathrm{ala}_{4}\right)$ was a little faster than with the free amino acid, but the dipeptide L-alanyl alanine inhibited growth. 
Minimal medium. The inorganic requirements, and those for fatty acids, sterol, spermine, nucleic acid precursors and glycerol have been discussed previously and were not considered further. The composition of the minimal medium giving the best growth of strain $\mathrm{Y}$ is listed in Table 2.

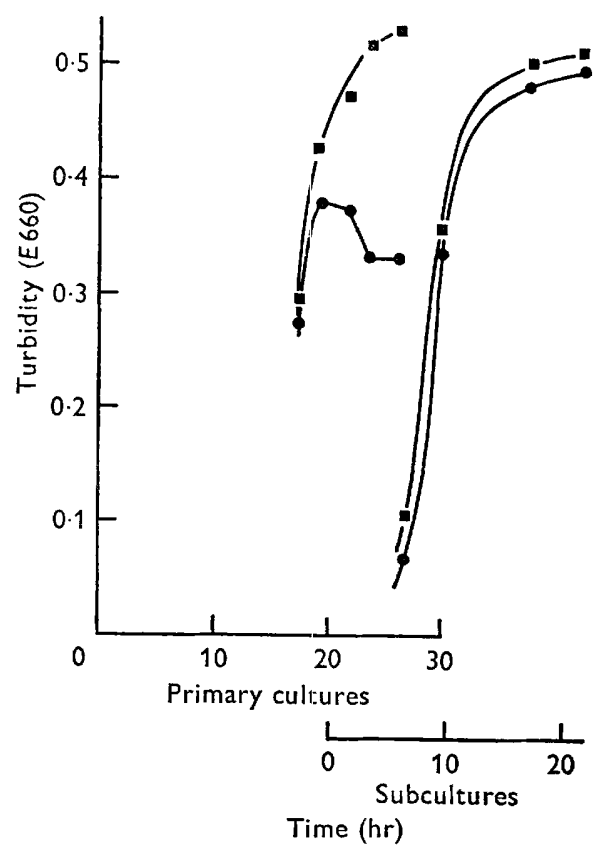

Fig. 4

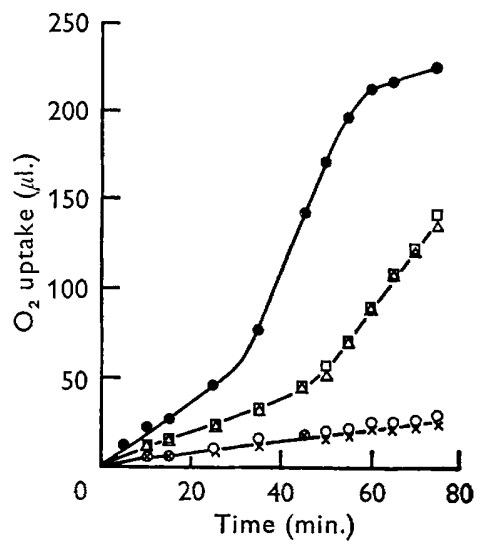

Fig. 5

Fig. 4. Effect of $\alpha$-lipoic acid on growth of Mycoplasma strain Y. Cultures in medium C2. घ, With DL- $\alpha$-lipoic acid $(0.2 \mu \mathrm{g} \mathrm{ml}$ ); $\bullet$, no $\alpha$-lipoic acid.

Fig. 5. Effect of $\alpha$-lipoic acid deficiency on pyruvate oxidase activity of Mycoplasma strain Y. Mycoplasmas were from subcultures for $20 \mathrm{hr}$ in medium $\mathrm{C}_{2}$ with $\alpha$-lipoic acid $(\alpha$-lipoic acid cells), and without $\alpha$-lipoic acid (deficient cells)-see Fig. 4. Manometer flasks contained: $\mathrm{Na}_{2} \mathrm{HPO}_{4}+\mathrm{KH}_{2} \mathrm{PO}_{4}, \mathrm{pH} 7 \cdot 4,200 \mu$ moles; sodium pyruvate, $20 \mu$ moles; DL- $\alpha$-lipoic acid, $10 \mu \mathrm{g}$., amino acids $3.5 \mathrm{mg}$.; $\alpha$-lipoic acid cells, $2.2 \mathrm{mg}$; deficient cells, $3.8 \mathrm{mg}$; $\mathrm{KOH}$ in centre well; fluid volume $2.5 \mathrm{ml}$. O, Deficient cells with $\alpha$-lipoic acid; $\times$, deficient cells without $\alpha$-lipoic acid; $O$, deficient cells with $\alpha$-lipoic acid but no pyruvate; $\square, \alpha$-lipoic acid cells with $\alpha$-lipoic acid; $\triangle, \alpha$-lipoic acid cells without $\alpha$-lipoic acid.

\section{Nutrition of other strains of Mycoplasma}

Mycoplasma mycoides strain v 5 did not grow in media in which TEM-4T replaced fatty acids and the protein fractions, even with the addition of a pronase digest of BSA to provide peptides and other growth factors. Several strains, including $\mathrm{V} 5$, were tested for growth in medium $\mathrm{C}$; none grew well, or in rotated tube cultures in medium $\mathrm{C}$ modified for aerobic growth conditions by increasing the glycerol concentration and adding lactate. Two strains of $M$. mycoides (v5 and GLADYSDALE), the bovine arthritis strains (N29 and L 2917), and a strain of M. mycoides var. capri (CHU) grew well in rotated tube cultures in medium $\mathrm{C}_{3}$, the growth rate and yield of organisms being about the same as that obtained with strain $\mathrm{Y}$ in medium $\mathrm{C} 2$. Mycoplasma 
Table 2. Composition of defined medium E for growth of

Mycoplasma strain $\mathrm{Y}$

Additions

Concentration

$\mathrm{Na}_{2} \mathrm{HPO}_{4}$

$\mathrm{KCl}$

$\mathrm{MgSO}_{4}$

O. I $4 \mathrm{M}$

$0.0 \mathrm{I} \mathrm{M}$

$0.001 \mathrm{M}$

$0.04 \mathrm{M}$

Glucose*

$0 \cdot \mathrm{I} \mathrm{mM}$

$0.2 \mathrm{~mm}$

Cholesterol $\uparrow$

$5.0 \mathrm{~mm}$

Glycerol

Diacetoxysuccinoyl esters of monoolein and monopalmitin (or TEM-4T) $†$

$0.04 \mathrm{~mm}$

(or $50 \mathrm{mg} . / 1$.

of TEM-4T)

Adenine, guanine, uracil

Thymine

Coenzyme A $\ddagger$, riboflavin*, nicotinamide, thiamine

DL- $\alpha$-lipoic acid

L-asparagine, L-glutamine*, L-arginine, L-lysine, L-histidine, L-leucine,

L-isoleucine, L-proline

DL-phenylalanine, DL-valine, DL-methionine, DL-serine, DL-threonine,

DL-tryptophan, glycine

L-cysteine*

L-alanylal-L-anyl-L-alanine

I0.0 $\mathrm{mg} / \mathrm{l}$. each

$5.0 \mathrm{mg} . / \mathrm{l}$.

I.0 mg./l. each

$0 \cdot \mathrm{I} \mathrm{mg} . / \mathrm{l}$.

I $\circ \mathrm{mm}$ each

$2 \cdot 0 \mathrm{~mm}$ each

I. $3 \mathrm{mM}$

$0.3 \mathrm{~mm}$

* Added from sterile solutions to previously autoclaved medium. Glutamine and cysteine solutions were freshly prepared.

$\dagger$ Aqueous dispersions prepared by the addition of solutions in ethanol to stirred water at $65^{\circ}$ for cholesterol, or at $20^{\circ}$ for TEM-4T and homologues.

$\ddagger$ Added before autoclaving from a $0.1 \mathrm{mg} . / \mathrm{ml}$. solution containing dithiothreitol, $\mathrm{I} \cdot 0 \mathrm{mg} . / \mathrm{ml}$. in phosphate buffer, $\mathrm{pH} 7 \cdot 0$.

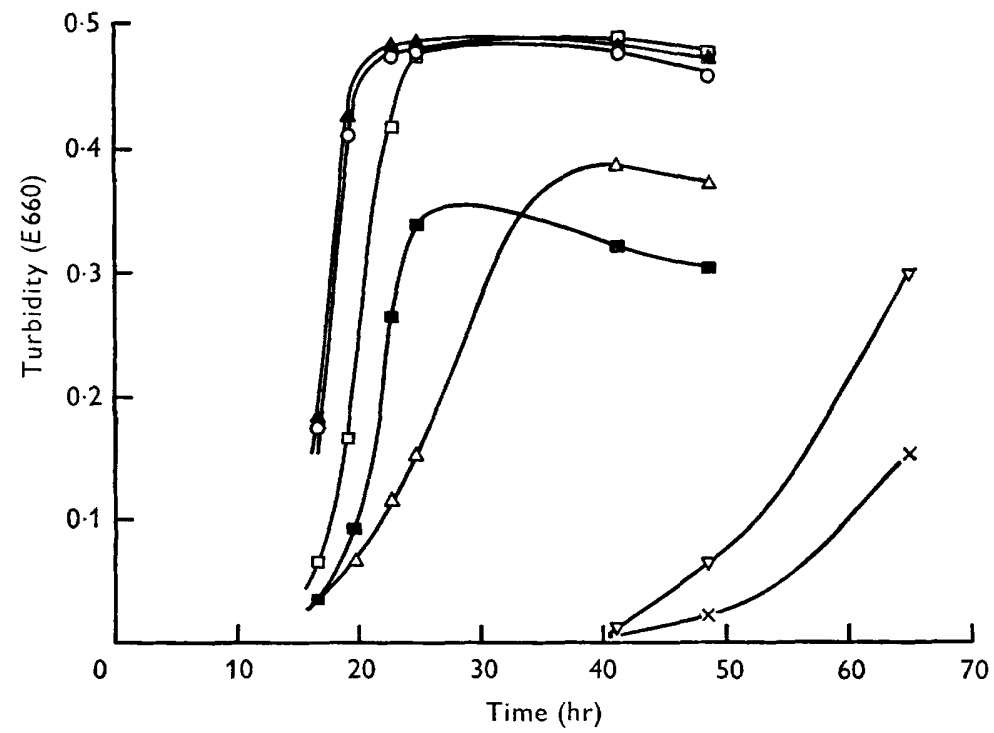

Fig. 6. Effect of L-alanine and L-alanyl peptides on growth of Mycoplasma strain Y. Medium E contained TEM-4T and L-alanine, peptides and pyridoxamine as indicated. $\times$, without L-ala, peptides or pyridoxamine; $\nabla$, without L-ala or peptides; $\square$, L-ala, I mm;

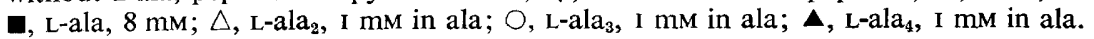


mycoides strain $\mathrm{KH}_{3} \mathrm{~J}$ grew poorly, while the s6 strain of $M$. gallisepticum gave no growth. The strains of $M$. mycoides and the bovine arthritis strains grew in medium $\mathrm{C}_{3}$ as extremely long, branched filaments.

Glycerol was essential for the Mycoplasma mycoides strains and for the strain of $M$. mycoides var. capri. Exogenous glycerol was not essential for the bovine arthritis strains, but they grew poorly without it, and the cells underwent lysis. Requirements for other nutrients were not determined, apart from the observations already reported for strain v 5 (Rodwell, I960).

\section{DISCUSSION}

The protein supplements might have contributed unrecognized nutrients for growth of strain $\mathrm{Y}$ in medium $\mathrm{C}_{2}$. To eliminate these it was necessary to substitute fatty acids in a non-toxic, chemically defined form, which would at the same time disperse cholesterol. Mixtures of 'Tweens' (polyoxyethylene sorbitan mono esters of fatty acids) were tried without success. Lund \& Shorb (1966) described a partially defined medium in which TEM-4 T provided fatty acids for growth of Mycoplasma strain J. TEM-4T contains a balanced mixture of saturated and unsaturated fatty acids, and gave good growth of strain $\mathrm{Y}$. The concentration required for optimum growth was much greater than in the medium of Lund \& Shorb, and the cholesterol concentration had to be increased in proportion. It is possible that an interaction between TEM-4 T and cholesterol modifies the surface active properties of the glycerides and disperses cholesterol. TEM-4 $\mathrm{T}$ was in turn replaced by synthetic homologues, enabling the minimal nutritional requirements to be determined.

TEM-4 T and the synthetic homologues do not seem to be completely non-toxic for mycoplasmas. Strain v 5 required both BSA (at an increased concentration) and fraction C (or PC) for good growth, and these could not be replaced by TEM-4T. While strain $\mathrm{V}_{5}$, and the other strains which grew well in medium $\mathrm{C}_{3}$, may require unrecognized nutrients (supplied by the protein supplements), it is also possible that TEM-4T is not a suitable source of fatty acids for them.

Other strains might be grown in partially defined media by including more complex mixtures of nucleic acid precursors (such as are required by Mycoplasma laidlawii strain B, Tourtellotte, Morowitz \& Kasimer, 1964), by altering the proportions of amino acids, or by adding arginine in high concentration as an energy source for growth of non-fermentative strains having the arginine dihydrolase pathway (Barile, Schimke \& Riggs, I966).

I wish to thank Professor J. M. Swan for advice on the synthesis and nomenclature of the diacetoxysuccinoyl esters of monoglycerides, Dr $\mathrm{H}$. Birnbaum for supplying me with a sample of TEM-4 T and Mr B. Zwolak for his capable technical help.

\section{REFERENCES}

BAER, E. \& FISCHER, H. O. L. (1945). Synthesis of a homologous series of optically active normal aliphatic $\alpha$-monoglycerides (L-series). J. Am. chem. Soc. 67, 203 I.

BARILE, M. F., SCHIMke, R. T. \& RigGS, D. B. (1966). Presence of the arginine dihydrolase pathway in Mycoplasma. J. Bact. 9I, I89.

BIRNBAUM, H. (1955). Emulsifiers as regulators of labile water distribution between protein and starch. Bakers' Dig. 29, IOI. 
Hartman, L. (1957). Glyceride synthesis by direct esterification. J. chem. Soc. p. 3572.

LAws, L. (1956). A pleuropneumonia-like organism causing peritonitis in goats. Aust. vet. J. $32,326$. Lowry, O. H., Rosebrough, N. J., Farr, A. L. \& Randall, R. J. (I95I). Protein measurement with the Folin phenol reagent. J. biol. Chem. 193, 265.

Lund, P. G. \& Shorb, M. S. (I966). Growth of Mycoplasma gallisepticum strain J without serum. Proc. Soc. exp. Biol. Med. 121, I070.

Rodwell, A. W. (1960). Nutrition and metabolism of Mycoplasma mycoides var. mycoides. Ann. N.Y. Acad. Aci. 79, 499.

Rodwell, A. W. (1963). The steroid growth requirement of Mycoplasma mycoides. J. gen. Microbiol. 32, 9 I.

RoDWEll, A. W. (1967). The nutrition and metabolism of Mycoplasma: progress and problems. Ann. N.Y. Acad. Sci. 143, 88.

Rodwell, A. W. (I969). The supply of cholesterol and fatty acids for the growth of mycoplasmas. J. gen. Microbiol. 58, 29.

Tourtellotte, M. E., Morowitz, H. H. \& Kasimer, P. (I964). Defined medium for Mycoplasma laidlawii. J. Bact. 88, I I. 